\title{
Effect of pancreas transplantation on diabetic retinopathy: a 20-case report
}

\author{
F. Bandello ${ }^{1}$, C. Vigano ${ }^{1}$, A. Secchi ${ }^{2}$, S. Martinenghi ${ }^{2}$, R. Caldara ${ }^{2}$, V. Di Carlo ${ }^{3}$, G. Pozza and R. Brancato $^{1}$ \\ Departments of ${ }^{1}$ Ophthalmology, ${ }^{2}$ Internal Medicine and ${ }^{3}$ Surgery, Istituto Scientifico San Raffaele, Milan, Italy
}

Summary. In order to study the effects of normoglycaemia on diabetic retinopathy, 20 diabetic uraemic patients who underwent a kidney-pancreas transplantation were evaluated before and after surgery (6,9 months and once a year). The control group consisted of 12 uraemic patients who underwent kidney transplantation alone. At each follow-up examination a complete clinical examination and a retinal fluorescein angiography were performed. The eyes with end-stage retinopathy at baseline were excluded from the study.The analysis of the results showed no significant differences in the two groups. The diabetic retinopathy at the moment of the transplantation was already too advanced to benefit from the better glycaemic control.

Key words: Diabetic retinopathy - Metabolic control Kidney and pancreas transplantation

\section{Introduction}

The role of metabolic control on the evolution of diabetic retinopathy has been widely explained, although a clear correlation has not been established (Hanssen 1986; Siperstein 1983).

A near normal glycaemic control is nowadays a possible target using one of following means: conventional insulin therapy and home blood sugar monitoring, multiple insulin injection or continuous subcutaneous insulin-delivery system. The main disadvantage of strict metabolic control is hypoglycaemia, so that a near normoglycaemia is obtained at risk of a higher incidence of hypoglycaemic episodes.

Pancreas transplantation is a self-regulated source of insulin and the only means of obtaining a near physiologic metabolic control without the occurrence of hypoglycaemia. The results of this technique have greatly improved recently (Sutherland 1987) and many groups are now evaluating its effect on long-term degenerative diabetic complications. We have studied the evolution of diabetic retinopathy in patients successfully submitted to a simultaneous pancreas and kidney transplantation. Twelve diabetic patients submitted to a kidney transplantation alone constituted the control group.

\section{Subjects and methods}

Twenty patients (39 eyes, 1 enucleated) submitted to a simultaneous kidney-pancreas transplantation from a cadaveric donor between July 1985 and August 1990 constituted the study group. The clinical characteristics of this group are shown in Table 1.

Table 1. Clinical characteristics

$\begin{array}{lcc} & \text { study group } & \text { control group } \\ \text { Number of patients } & 20 & 12 \\ \text { Age years a } & 41.3 \pm 8.1 & 37.7 \pm 7.6 \\ \text { Sex M/F } & 8 / 12 & 5 / 7 \\ \text { Diabetes duration years a } & 25.1 \pm 6.7 & 23.5 \pm 5.0 \\ \text { Dialysis duration months a } & 17.7 \pm 13.5 & 17.9 \pm 10.5\end{array}$

$a_{m \pm S D}$

Sixteen patients received a segmental neoprene injected pancreas and 4 patients received a whole pancreas with bladder diversion. Immunosuppression consisted of anti-lymphocyte globulins, azathioprine, prednisone and cyclosporin. In all cases insulinindependence was achieved within 1 or 2 week after surgery. A good metabolic control was maintained during the follow-up (see Table 2). 
Table 2. Groups of patients according to the different follow-up periods and mean value of the considered parameters

\begin{tabular}{|c|c|c|c|c|c|c|}
\hline \multicolumn{3}{|c|}{ Follow-up years $>3$} & \multicolumn{2}{|c|}{1.3} & \multicolumn{2}{|l|}{$<\mathbf{I}$} \\
\hline $\begin{array}{l}\text { Type of } \\
\text { patients }\end{array}$ & $\mathbf{S}$ & C & $\mathbf{S}$ & $\mathrm{C}$ & $\mathbf{S}$ & $\mathrm{C}$ \\
\hline Number & 7 & 4 & 8 & 6 & 5 & 2 \\
\hline HbAlC\%a & $\begin{array}{l}\mathbf{6 . 5} \\
(1.0)\end{array}$ & $\begin{array}{l}6.6 \\
(0.9)\end{array}$ & $\begin{array}{l}6.1 \\
(0.8)\end{array}$ & $\begin{array}{l}7.5 \\
(0.3)\end{array}$ & $\begin{array}{l}6.2 \\
(3.2)\end{array}$ & $\begin{array}{l}8.9 \\
(1.9)\end{array}$ \\
\hline $\begin{array}{l}\text { Serum } \\
\text { creatinine } \\
(\mathrm{mg} / \mathrm{dl})\end{array}$ & $\begin{array}{l}1.2 \\
(0.4)\end{array}$ & $\begin{array}{l}1.7 \\
(0.5)\end{array}$ & $\begin{array}{l}1.1 \\
(0.1)\end{array}$ & $\begin{array}{l}2.0 \\
(0.9)\end{array}$ & $\begin{array}{l}1.9 \\
(2.2)\end{array}$ & $\begin{array}{l}1.6 \\
(0.7)\end{array}$ \\
\hline
\end{tabular}

$S=$ study group, $C=$ control group

$a_{\text {mean }} \pm$ SEM

Twelve diabetic uraemic patients constituted the control group (23 eyes, 1 enucleated). Their clinical characteristics, shown in Table 1 , were comparable to the study group. Among them, 7 received a kidney transplantation alone and 5 received a simultaneous kidney and pancreas graft, but lost the pancreatic function within the first month after surgery (mainly for technical reasons). Immunosuppression was the same in the study group. A good metabolic control was achieved with insulin therapy (multiple injection regimen in 4 cases and subcutaneous insulin infusion in 8 cases) throughout the follow-up.

Ophthalmological evaluations. In both groups patients underwent an ophtalmological evaluation before surgery and 6 and 9 months and yearly intervals thereafter. The patients were divided into 3 groups, according to the follow-up (see Table 3).

Table 3. Mean variation of visual acuity in the study group and in the control group according to the follow-up

\begin{tabular}{lllllll}
\hline $\begin{array}{l}\text { Follow-up years }>3 \\
\text { Type of } \\
\text { patients }\end{array}$ & $\mathrm{S}$ & $\mathrm{C}$ & $\mathrm{S}^{1.3}$ & $\mathrm{C}$ & $\mathrm{s}^{<} \mathrm{C}$ \\
& & & & & & \\
$\begin{array}{l}\text { Initial } \\
\text { visual acuity a }\end{array}$ & 0.4 & 0.8 & 0.7 & 0.5 & 0.7 & 0.8 \\
& $(0.3)$ & $(0.3)$ & $(0.2)$ & $(0.4)$ & $(0.2)$ & - \\
$\begin{array}{l}\text { Final } \\
\text { visual acuity a }\end{array}$ & 0.4 & 0.8 & 0.7 & 0.6 & 0.8 & 0.8 \\
& $(0.3)$ & $(0.3)$ & $(0.2)$ & $(0.4)$ & $(0.2)$ & -
\end{tabular}

$S=$ study group, $C=$ control group

$a_{\text {mean }} \pm \mathrm{SD}$

A complete ophthalmological examination, determination of the best corrected visual acuity and a fluorescein angiography were performed. The end point for data collection was the most recent examination performed for each patient. Fluorescein angiograms were evaluated by two different ophthalmologists separately. Angiograms were evaluated for : capillary closure, macular oedema, disk neovascularization, neovascularization elsewhere, vitreous haemorrhage. Visual function was also examinated. The evaluations were performed separately in the 3 groups of follow-up (see Table 3). Nine eyes were excluded at baseline because of neovascular glaucoma or secondary retinal detachment. Ten eyes were ruled out from the study because one of the following eventualities occurred during the follow-up: laser treatment, cataract extraction, anterior ischaemic optic neuropathy, cytomegalovirus retinitis.
Results

For the reasons mentioned above, 19 eyes in the study group (48.7\%) and 11 eyes in the control group $(47.8 \%)$ were ruled out from the study. In the study group the causes for the exclusion were: end stage retinopathy ( 9 eyes $47.3 \%$ ), laser treatment ( 8 eyes $42.1 \%$ ), cataract extraction + laser treatment ( 1 eye $5.3 \%$ ), anterior ischaemic optic neuropathy (1 eye $5.3 \%$ ). In the control group, 10 eyes (90.9\%) were excluded because of laser treatment and $1(9.1 \%)$ because of cytomegalovirus endophthalmitis. Prior to surgery 14 eyes $(70 \%)$ in the study group and 7 $(58.3 \%)$ in the control group had been panphotocoagulated. No changes were observed in 18 eyes (90\%) in the study group and in 8 eyes $(66.7 \%)$ in the control group. Two eyes both in the study and in the control group showed a reduction of the macular oedema and capillary closure; 2 eyes in the control group showed an augmented capillary closure. The mean visual acuity did not change significantly in any group during the follow-up (see Table 3 ) nor did it change when each patient was considered separately or among the different groups of follow-up.

\section{Discussion}

The aim of this study was to evaluate the potential benefit of normoglycaemia on the evolution of diabetic retinopathy, as a mean to reverse or, at least, stabilize the ophthalmological complications of diabetes. The control group was comparable to the study group for age, diabetes duration, dialysis duration and immunosuppressive therapy. Our data show no difference between the study and the control group, and similar results had been reported by other authors (Petersen 1990; Ramsay 1988; Bandello 1989). On the other hand, other groups have suggested positive effects of pancreas transplantation on diabetic retinopathy (Black 1981; Ulbig 1987; Konisgrainer 1986) If our results are not encouraging, we have to underline that the baseline ocular status of our patients was far advanced before surgery and maybe not susceptible to amelioration. Diabetic retinopathy substantially stabilized after kidney+pancreas or kidney transplantation, and an experienced ophthalmologist should be responsible for such a stabilization on followup. When end-stage diabetic nephropathy develops, it is often associated with severe retinal damage; until pancreas transplantation is performed at late stage of the disease, it will hardly exert a benefical effect on diabetic retinopathy. 


\section{References}

Bandello F, Viganò C, Secchi A, La Rocea E, Spotti D, Caldara R, Staudacher C, Carlucci M, Castoldi R, Di Carlo V, Brancato R, Pozza G (1989) Diabetic retinopathy in patients submitted to successful kidney pancreas allotransplantation.

Diabetes 38,1: 265

Black PD (1981) Visual status of diabetic patients after pancreatic and other organ transplantation: preliminary report.

Trans Ophtalmol Soc. UK 101: 100-104

Hanssen KF, Dahl-Jorgensen K, Lauritzen T, Feldt- Rasmussen B, Brinchmann-Hansen O, Deckert T (1986) Diabetic control and microvascular complications: the near normoglycaemic experience. Diabetologia 29:667-684

Konigsrainer A, Miller K, Kieselbach G, Ofner D, Tauscher T, Dunser M, Margreiter R (1990) Course of diabetic retinopathy after pancreas transplantation. Transplant Proc 22:689-690

Petersen MR, Vine AK, The University of Michigan Pancreas Transplant Evaluation Commitee (1990) Progression of diabetic retinopathy after pancreas transplantation.

Ophtalmology $97: 496-502$

Ramsay RC, Goetz FC, Sutherland DER, Mauer SM, Robison LL, Cantrill HL, Knobloch WH, Najaria JS (1988) Progression of diabetic retinopathy after pancreas transplantation for insulin dependent diabetes mellitus.

N Engl J Med 318:208-214

Siperstein MD (1983) Diabetic microangiopathy and the control of blood glucose. N Engl J Med 309:1577-1579

Sutherland DER, Mondry KC (1987) Pancreas transplantation: North American versus European experience. Transpl Proc 19: 3867-3869

Ulbig M, Kampik A, Landgraf R, Land W (1987) The influence of combined pancreatic and renal transplantation on advanced diabetic retinopathy. Transpl Proc 19: 3554-3556

\section{Prof. R.Brancato}

University of Milan Department of Ophthalmology Istituto Scientifico San Raffaele 20132 Milan

Italy 